\title{
AS TECNOLOGIAS DE INFORMAÇÃO E COMUNICAÇÃO COMO POSSIBILIDADE DE MELHORIAS DA EDUCAÇÃO
}

\author{
Vera Adriana Huang Azevedo Hypólito ${ }^{1}$, Katia Maria Roberto de Oliveira Kodama ${ }^{2}$ \\ ${ }^{1}$ ETEC Jacinto Ferreira de Sá - CEETEPS. Ourinhos - SP. E-mail: vera.hypolito@etec.sp.gov.br. ${ }^{2}$ Universidade Estadual \\ Paulista - FCT/UNESP. Presidente Prudente - SP.
}

\begin{abstract}
RESUMO
O presente trabalho apresenta considerações sobre a inserção das Tecnologias da Informação e Comunicação (TICS) no processo de ensino aprendizagem. Supõe-se que as TICs promovem melhorias no ensino, transportando para o ambiente escolar a realidade estética visual. $O$ ensino deve prover uma integração entre a realidade escolar e a realidade vivenciada pelos alunos constantemente bombardeados pelas novas produções visuais. Analisando o material didático destinado ao Ensino Médio em relação à proposta deste texto, foi verificado que é necessário uma evolução. A análise apresentada é motivada pelo desejo de contribuir para ampliar as ofertas de formação através da imagem, da arte - visualidades, da presença da TICs nas escolas para integrar as culturas, enriquecer o vocabulário, apresentar outras possibilidades estéticas para suscitar escolhas, ampliar as noções de alfabetização visual e instrumentalizar os alunos para efetivarem juízos conscientes e críticos na contemporaneidade.
\end{abstract}

Palavras-chave: TICs, ensino aprendizagem, alfabetização visual, material didático, culturas.

\section{THE INFORMATION TECHNOLOGY AND COMMUNICATION AS A POSSIBILITY OF IMPROVEMENT OF EDUCATION}

\begin{abstract}
This paper presents considerations regarding the integration of Information and Communication Technologies (ICT) in the teaching learning process. It is assumed that ICTs promote improvements in teaching, school environment for carrying visual aesthetic reality. The school must provide an integration between the school reality and the reality experienced by the students constantly bombarded by new visual productions. Analyzing the didactic material for the high school on the proposal of this paper, it was found that a change is needed. The analysis is motivated by the desire to contribute to expanding training opportunities through the image, art - visual arts, the presence of ICT in schools to integrate cultures, enrich vocabulary, present other opportunities to raise aesthetic choices, expand the notions visual literacy and prepare students to actualize conscious and critical judgments in contemporary times.
\end{abstract}

Keywords: ICT, teaching and learning, visual literacy, teaching materials, cultures. 


\section{INTRODUÇÃO}

O presente trabalho apresenta considerações sobre a contribuição da inserção das Tecnologias da Informação e Comunicação (TICS) no processo de ensino aprendizagem como forma de introduzir uma educação visual, visto que nos materiais didáticos presentes nas escolas das redes públicas e também particulares destinados ao Ensino Médio não existem a preocupação de promover uma alfabetização visual.

Parte-se da hipótese de que as tecnologias promovem melhorias no ensino, enriquecendo o processo de construção do conhecimento e transportando para o ambiente escolar a realidade estética visual vivenciada pelos educandos e educadores. Para implementar a análise e apresentar resultados foi elaborada uma pesquisa de cunho qualitativo e bibliográfico. Preconiza-se que o ensino deve prover uma integração entre a realidade escolar e a realidade vivenciada pelos alunos constantemente bombardeados pelas produções visuais da contemporaneidade.

A escola apresenta-se completamente desvinculada das visualidades vivenciadas pelos seus integrantes - professores e alunos. Esse distanciamento visual pode ser denominado de estética escolar e tem sua origem nos livros didáticos com formatação e diagramação visual restrito aos materiais produzidos nas primeiras décadas do século passado. Ainda é evidente que a organização espacial dos ambientes escolares remontam a uma dinâmica de ensino aprendizagem em que os alunos eram tratados como receptores passivos do conhecimento.

$\mathrm{Na}$ atualidade, a escola ainda não percebeu que essas visualidades são fatores importantes para desencadear um pertencimento e aproximação dos educandos com o conhecimento. Ela se mantém fiel a suas estruturas de séculos passados, porém, seus protagonistas chegam influenciados por novas mídias, novas visualidades e novos recursos.

Todos os atores que vivenciam os processos educativos são portadores, reprodutores e consumidores de valores culturais, estéticos e visuais. Essa dinâmica pode e deve ser considerada no ensino para gerar, como propõe Paulo Freire, "Práticas Educativas Emancipadoras". (FREIRE, 1983). Uma Educação "Emancipadora" permite vislumbrar propostas de mudança social através da descodificação do mundo e da inserção consciente nele. Nesse sentido as TICs podem desempenhar um papel fundamental para transportar a escola para a realidade contemporânea. Moran (2008, p.7) coloca que "a escola é pouco atraente" e que as tecnologias permitem realizar uma revolução na educação, tornando o processo de ensino aprendizagem mais dinâmico e ativo.

Logo, as relações entre as manifestações culturais visuais e as linguagens das artes que imperam na contemporaneidade, bem como as TICs, devem se imbricar podendo ser vistas como constitutivas de uma formação comprometida com as práticas e representações sociais das 
comunidades, principalmente quanto aos conteúdos culturais veiculados pelos meios massivos de difusão e comunicação, predominantemente visuais e com manifestações presentes em nosso cotidiano.

Por esse motivo, a expressão cultura visual refere-se a uma diversidade de práticas e interpretações críticas em torno das relações entre as posições subjetivas e as práticas culturais e sociais do olhar. Desse ponto de vista, quando me refiro neste livro à cultura visual, estou falando do movimento cultural que orienta a reflexão e as práticas relacionadas a maneiras de ver e de visualizar as representações culturais e, em particular, refiro-me às maneiras subjetivas e intra-subjetivas de ver o mundo e a si mesmo. (HERNÁNDEZ, 2007, p.22).

No Brasil, as décadas de Vargas e o período desencadeado após o golpe de 1964 foram decisivos para excluir da educação atitudes como: valoração dos sentimentos, sensibilidade, emoção e os sentidos de pertencimento vinculados às culturas regionais e locais como parte da formação das crianças (RIBEIRO, 1982). Foi preciso que a sociedade e a escola se desintegrassem na "Modernidade Líquida" (BAUMAN, 2003) para que se iniciasse e retomasse o caminho do sensível e da subjetividade como possibilidade educativa, da valoração das culturas locais e de uma educação voltada para os sentimentos do homem, pois como afirma Freire, "Não há educação fora das sociedades humanas e não há homem no vazio" (FREIRE, 1993, p. 43).

Vive-se o momento dialético do início de um século que não permitirá ao homem ser como antes, conclamando-o a construir um humanismo novo para o milênio em curso, numa urgência até então desconhecida pela própria história. Freire aponta para o imbricamento entre tempo e cultura/arte:

Herdamos a experiência adquirida, criando e recriando, integrando-se às condições de seu contexto, respondendo a seus desafios, objetivando-se a si próprio, discernindo, transcendendo, lança-se o homem num domínio que lhe é exclusivo - o da História e o da Cultura. (FREIRE, 1993, p 41).

A redenção para nosso tempo ainda está nos meios de formação formal dos processos de aprendizagens como endossa o relatório Dellors (DELORS, 2001, p.99) “a educação deve contribuir para o desenvolvimento total da pessoa - espírito e corpo, inteligência, sensibilidade, sentido estético, responsabilidade pessoal e espiritualidade", e propõe no mesmo texto os pilares de uma educação para o século XXI, que consiste em "aprender a conhecer", "aprender a fazer", "aprender a viver juntos" e "aprender a ser" (DELORS, 2001, p. 31). Assim, esse texto tem por objetivo apresentar considerações elaboradas a partir de uma análise preliminar para desenvolver futuros estudos que visam discutir o uso das novas Tecnologias da Informação e Comunicação 
como ferramentas para promover a melhoria do ensino no Ensino Médio frente ao desinteresse demonstrado pelos alunos quanto ao uso dos materiais didáticos a eles destinados.

\section{METODOLOGIA}

Esse texto foi elaborado a partir de uma pesquisa bibliográfica preliminar sobre cultura visual, bem como sobre o uso das novas Tecnologias da Informação e Comunicação. Também expressa uma análise qualitativa da visualidade dos materiais didáticos presentes principalmente nas redes públicas de ensino provenientes do governo federal e do Estado de São Paulo destinados ao Ensino Médio nas cidades de Ourinhos e Presidente Prudente e como a realidade visual e estética promovida pelas TICs podem auxiliar na integração das comunidades escolares com o cotidiano promovendo a alfabetização visual.

Portanto, optou-se por não nominar os materiais pesquisados visto que o objetivo foi o levantamento de conhecimentos prévios para desencadear uma pesquisa mais elaborada e fundamentada, tendo como protagonistas os integrantes do processo educativo e suas impressões quanto aos suportes didáticos que lhes são destinados, pelas instâncias oficiais que promovem o ensino, e o papel da escola frente às novas TICs e como elas apresentam considerações referentes às culturas visuais na atualidade.

\section{RESULTADOS}

Analisando o material destinado ao Ensino Médio quanto aos aspectos a que se propõe esse texto, acredita-se que cabe à escola elaborar propostas viáveis para serem trabalhadas na busca de uma educação que satisfaça as necessidades dos alunos e da sociedade, entendidos como um organismo vivo do seu tempo e das culturas locais.

Não é a condição social ou cultural que determina as capacidades cognitivas das pessoas na atualidade, também a escola não é o espaço decisivo que promove aprendizagem. Afirmar isso só reforça o caráter determinista que a escola tomou para si em séculos passados. Em um mundo marcadamente visual e cercado de mídias tecnológicas de comunicação essas afirmações não se enquadram mais.

A sociedade do conhecimento, por meio das novas Tecnologias de Informação e Comunicação TICs, tem multiplicadas as formas de acesso, compreensão, circulação e produção de conhecimento com os quais convivemos. Assim também na Educação, a tecnologia promove mudanças no processo de conhecimento, interação, comunicação e na formação, tanto de alunos quanto de professores. 
Nesse ambiente digital, tudo se altera com extrema rapidez: conhecimentos, saberes, informações e comportamentos que são refletidos nas formas de agir de pensar e educar da sociedade moderna. Segundo Kenski (1998), para tornar possível significativas mudanças no processo educativo, as TICs devem ser conhecidas e compreendidas.

$\mathrm{Na}$ atualidade, os alunos lidam com muita propriedade com celulares, jogos virtuais, cartões magnéticos, cartazes e sites de promoção e compras virtuais, entre outros, que caracteriza a visualidade do mundo contemporâneo, esse domínio configura-se como um novo saber, e, a escola não leva em consideração esses conhecimentos, geralmente nega ou proíbe que adentre aos seus domínios. Existe um descompasso entre o que os alunos sabem e dominam e o que a escola espera que os alunos saibam. Os "levantamentos prévios" desconsideram esses saberes dos alunos.

Na escola, os materiais didáticos destinados a esses mesmos alunos não acompanham esse movimento compreendido e apreendido pelos mesmos. Em sua maioria, o que é destinado para a escola apresenta-se revestido de uma visualidade vinculada a um universo do início do século passado. Seus textos, sua espacialidade, sua dinâmica de promover o conhecimento não levam em consideração que os alunos do Ensino Médio chegam ao ambiente escolar dominando e, principalmente, sendo influenciados, pelo mundo da tecnologia. Suas opiniões são formadas por elas e seus domínios cognitivos implementados por outra lógica de pensamento.

É a escola que não introduz e ou compreende esses mecanismos para atender os alunos, como exemplo pode-se citar que a grande maioria das escolas não faz uso de computadores como recurso para dinamizar as aulas embora, no Estado de São Paulo, quase todas possuam laboratórios de informática.

\section{DISCUSSÃO}

Nesse mundo globalizado a arte e a visualidade são, segundo Lucia Santaella (2003), os veículos comunicacionais que estão impregnados de síntese do presente, mas que sempre aponta para o futuro, pois se encontram próximos dos "enigmas do real".

As manifestações visuais são sempre um acontecimento coletivo, pois envolve, necessariamente, um produtor ou produtores, o contato com diferentes saberes e ofícios e um receptor ou receptores. São compostas por um conjunto formal de procedimentos tecnológicos e atitudes que refletem as formas de pensar e agir de uma comunidade.

Desta forma, sob a ótica dos estudos de cultura visual, é possível compreender que as representações imagéticas e os objetos estéticos produzidos pelas novas tecnologias cumprem 
dupla função: auxiliar no entendimento e perpetuação das práticas ritualísticas e simbólicas aglutinadoras dos grupos das culturas populares subalternas, e propiciar uma reflexão crítica sobre as inúmeras conceituações empregadas para compreender e classificar os gêneros das múltiplas linguagens de expressões na atualidade.

Segundo Sancho, Hernández \& cols. (2006, p. 75)

Para favorecer a construção de conhecimento, de uma perspectiva formativa inovadora, é necessário fomentar, em muitos casos por meio da utilização de tecnologias, tipos de situações com as seguintes:

- Contextos ricos em fontes e materiais de aprendizagem.

- Cenários que favoreçam a interação social.

- Propostas que favoreçam a transferência de aprendizagem (sic) em novos contextos.

- Fórmulas que permitam reconceituar a avaliação educativa.

- Problemas a resolver que exijam estudantes mais ativos e responsáveis.

Estamos em uma fase de mudanças socioculturais, com revisão de paradigmas que até a pouco tempo vigoravam como forma correta de conhecimento (HYPOLITTO, 2009).

Desta forma, a escola precisa dominar as linguagens contemporâneas, isto é, saber comunicar-se através dessas linguagens e/ou ferramentas.

\section{CONCLUSÕES}

É nas diferentes relações comunicacionais que as atividades humanas são caracterizadas. $\mathrm{Na}$ atualidade as relações com a visualidade e difusão de novas estéticas difundidas pelas TICs é vital, quase orgânica, esta entranhada nas subjetividades das pessoas. A comunicação visual não é um fenômeno isolado, nem restrito à contemporaneidade, pois interage com as manifestações culturais de cada comunidade desde seus primórdios assim como as artes que sempre carregam e se manifestam por visualidades, e, na atualidade essas visualidades estão sofrendo uma evolução incontrolada.

A velocidade com que as informações são produzidas criam uma macrocircularidade de informações e forçam os pesquisadores da Teoria da Informação e Comunicação, da Cultural Visual, das Artes e da Educação a voltarem sua atenção para o local, para o global e principalmente para o virtual.

O sociólogo Ciro Marcondes Filho (2004, p.15) afirma que "viver é estar comunicando, emitindo sinais, demonstrando participar do mundo". Neste sentido, propõe outro conceito de comunicação: "Comunicação é antes um processo, um acontecimento, um encontro feliz, um momento mágico entre duas intencionalidades", e ser capaz de criar: 
[...] um ambiente comum em que os dois lados participam e extraem de sua participação algo novo, inesperado, que não estava em nenhum deles, e que altera o estatuto anterior de ambos, apesar de as diferenças individuais se manterem (MARCONDES FILHO, 2004, p.15).

Conforme as concepções acima apontadas, os materiais didáticos destinados ao Ensino Médio, analisados, não contribuem para inserir e nem promover uma educação que vá ao encontro de uma formação atualizada. Existe uma contradição entre o que se propõe e como são elaborados e diagramados.

Como conclusão preliminar é importante afirmar que os livros estão prestando um desserviço na formação da consciência crítica de nossos alunos e professores.

Pela primeira vez na história, percebemos que a educação não acontece só durante um período determinado de tempo, maior ou menor (educação básica, superior), mas ao longo da vida de todos os cidadãos e em todos os espaços. [...] As sociedades sempre encontraram suas formas de educar. Quanto mais avançadas, mais complexas se tornam seus processos de ensinar. (MORAN, 2008, p 15).

Portanto, a análise apresentada é motivada pelo desejo de contribuir para ampliar as ofertas de formação através da imagem e da arte, promover as culturas das comunidades, enriquecer o vocabulário, apresentar outras possibilidades estéticas para suscitar escolhas e ampliar as noções de alfabetização visual e instrumentalizar os alunos para efetivarem escolhas conscientes e críticas quanto às ofertas de conteúdos oferecidos pelas TICs. MORAN $(2008$, p. 22) indica que: "A escola e a universidade precisam reaprender a aprender, a ser mais úteis, a prestar serviços mais relevantes à sociedade, a sair do casulo em que se encontram."

\section{REFERÊNCIAS}

BAUMAN, Z. Modernidade Liquida. Trad. Plínio Dentzien. Belo Horizonte: Zahar Editora, 2001.

DELORS, J. Educação: um tesouro a descobrir. Brasília, DF: Unesco, 200. Relatório para a Unesco da Comissão Internacional sobre Educação para o século XXI.

ecc1c57966/3229-10605-1-PBSantaella.htm. Acesso em: 25/-5/2014.

FREIRE, P. Educação e mudança. 21 ed. Rio de Janeiro: Paz e Terra, 1993.

Educação como Prática da Liberdade. 15 ed. Rio de Janeiro: Paz e Terra, 1983.

HERNÁNDEZ, F. Catadores da Cultura Visual. Proposta para uma narrativa educacional. Porto Alegre: Mediação, 2007. 
HYPÓLITTO, D. Formação docente em tempos de mudança. Integração: ensino, pesquisa, extensão. São Paulo, ano XV, n.56, p.91-95, jan/fev/mar. 2009. Disponível em: < http://www.usjt.br/proex/arquivos/produtos_academicos/91_56.pdf>. Acesso em: 04/05/2014.

KENSKI, V. M.. Novas tecnologias: redimensionamento do espaço e do tempo e os impactos no trabalho docente. Reunião Anual da ANPED, XX, Caxambu, setembro de 1997. Revista Brasileira de Educação. N.8, Mai/Jun/Jul/Ago, $1998 . \quad$ Disponível em: <http://educa.fcc.org.br/pdf/rbedu/n08/n08a06.pdf>. Acesso em: 24/05/2014.

MARCONDES FILHO, C. Até que ponto, de fato, nos Comunicamos? São Paulo: Paulus, 2004.

MORAN, J.M. A educação que desejamos: novos desafios e como chegar lá. 3 ed. Campinas: Papirus, 2008.

SANCHO, J.M.; HERNÁNDEZ, F. e Cols. Tecnologias para transformar a educação. Porto Alegre: Artmed, 2006.

SANTAELLA, L. Da cultura das mídias à cibercultura: o advento do pós humano. Rev. FAMECOS, Tecnologias Do Imaginário. Porto Alegre. no 22. Dez. 2003, p. 23 - 32, quadrimestral, 2003. Disponível em: http://www.sharepdf.com/b6b20091766f4b138ad95 